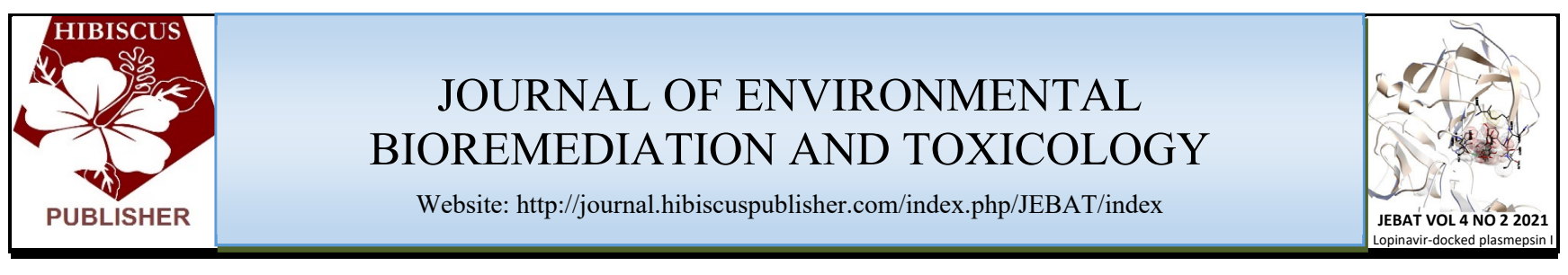

\title{
Consistent Organochlorinated Pesticides (OPC) Residues Contamination in Beans Consumed in Gombe Metropolis Nigeria
}

\author{
Usman, Y.M. ${ }^{1 *}$ and Hamza, A.P. ${ }^{1}$ and S. Abubakar ${ }^{1}$ \\ ${ }^{1}$ Department of Chemistry, Faculty of Science, Gombe State University Tudun wada, \\ Gombe P.M.B. 127 Gombe, Gombe State, Nigeria. \\ *Corresponding author: \\ Dr. Usman Yakubu Mohammed, \\ Department of Chemistry, \\ Faculty of Science, \\ Gombe State University, \\ P.M.B 127, Gombe, \\ Gombe state, \\ Nigeria \\ Email: usmanym45@gmail.com
}

\begin{tabular}{l}
\hline HISTORY \\
Received: $3^{\text {rd }}$ Aug 2021 \\
Received in revised form: $14^{\text {th }}$ Oct 2021 \\
Accepted: $19^{\text {th }}$ Nov 2021 \\
\hline KEYWORDS \\
Pesticide residues \\
Dried beans \\
Organochlorine \\
DDT \\
Lindane
\end{tabular}

\begin{abstract}
Most of the locally consumed beans in our vicinity contain excess chemicals of pesticides residues which are harmful to humans and environmental hazards to ecosystem. Investigation of this study revealed contamination level of organochlorine pesticides residues in dried beans originating from Nigeria with a view to controlling them, it also studies crude fiber of beans showed that B4 has the highest fiber content, $27.85 \%$ and the order of decreasing value as B4, B5, B1, B3 and B2. The least percentage of crude fiber was shown by B2 in all the beans samples analyzed. This study also investigated the pesticides residue components of the organochlorinated pesticides test. The presence of pesticide residues in all 14 types of organochlorine pesticides in beans is lower than a previously reported level. Despite this, the amount of organochlorine pesticides tested is more than the permitted levels of 0.01 to $0.2 \mathrm{mg} / \mathrm{kg}$, indicating that the beans consumed in the Gombe metropolis included pesticide residues beyond the permissible limit.
\end{abstract}

\section{INTRODUCTION}

Frequent utilization of pesticides through agricultural practice has protected crops against destructive pests and pesticide use has improved crop yield. Foods associated with these residue causes impacts to humans, animals and environmental hazard to the ecosystem, Organochlorinated Pesticides (OCP) originated from chemical pesticides residue from the farm [1-7].

Pesticides residues usage were intended to kill pests by disrupting their nervous system, which corresponds to the biochemistry among many different organisms. Reports also showed that these chemicals can harm humans as well as stated by Popp et al. [8]. Epidemiological studies showed positive correlations between exposure to pesticides through the occupational hazard, which tends to the significantly higher than the ingested by the general population through food and the occurrence of certain cancers [9-12]. Most of the general population which tend to be exposed to a large portion of pesticides were affected by pesticides residues that are attached to their lipophilic and can be bio-accumulate in their body systems $[13-15,11,16]$. Eating an organic diet can remedy the harmful effects of children's exposure to pesticides. Studies have found that children who eat conventional diets have significantly higher levels of OP pesticide metabolites in their urine than do children who eat organic diets [17]. According to the research by Isegbe [18], who revealed that the presence of endrin-aldehyde, heptachlor epoxide, endosulfan I and in the sampled dried beans was investigated. These results, therefore, provided baseline information on the contamination level of organochlorine pesticides residues in dried beans originating from Nigeria with a view to controlling them. The highest level of diazinon organochlorine phosphate was detected the day after the spraying of station 1 in the amount of $1.14 \mathrm{ppm}$. Generally, in the other stations, the mean level of diazinon pesticides residue was lower than the standard acceptable levels as previously reported [19].

\section{MATERIALS AND METHODS}

\section{Sample Collection}

Five different samples of beans commonly consumed in Gombe have collected altogether. Samples were identified with local names and coded as $\mathrm{B} 1=$ brown beans, $\mathrm{B} 2=$ Bossoc beans, $\mathrm{B} 3=$ Yabbarere, B4 = Kanannado and B5 known as Farin wake from Gombe. These different samples of beans were collected from two major markets in Gombe Metropolis. Then two corresponding samples were mixed together to form 
representative fractions suitable for the analysis as adopted by [20].

\section{Sample Preparation}

The homogeneous beans samples were grounded and sieved with sieve size 20 . The sieve samples ( $20 \mathrm{~g}$ each) were weighed and mixed with $100 \mathrm{~cm}^{3}$ of petroleum ether. The mixture was transferred into a separator and vigorously shaken for 1-2 minutes. Then $10 \mathrm{~cm}^{3}$ sodium chloride and $600 \mathrm{~cm}^{3}$ of distilled water were added. The separator was placed in a horizontal position for mixing that allowed to be mixed. The aqueous layer was discarded, and the solvent was washed twice with $100 \mathrm{~cm}^{3}$ distilled water. Then $15 \mathrm{~g}$ anhydrous Sodium sulphate was added and shaken vigorously and left for $1 \mathrm{~h}$ to prevent loss of organochlorine pesticides by adsorption. The mixed samples were extracted with Acetonitrile together with aliquot or nonfatty foods. The entire solution of the samples was diluted with $\mathrm{H}_{2} \mathrm{O}$ and the pesticides residues were extracted with petroleum ether. Further purification was done by column chromatography using eluting solvents of petroleum ether and diethyl ether. Residues in concentrated eluates were measured by GasChromatography-Mass Spectrometry (GC-MS) and identified by a combination of Gas - Chromatography as adopted by [21].

\section{RESULTS AND DISCUSSIONS}

\section{Crude fiber of beans}

The result of crude fiber analysis of the beans shows the insoluble residue of acid hydrolysis. The quantity of indigestible cellulose and other components in all the samples were measured as shown in Fig. 1. The data showed that B4 has the highest crude fiber content in decreasing order of $27.85 \%>\mathrm{B} 5=27.16 \%>\mathrm{B} 1=$ $20 \%>\mathrm{B} 3=12.55 \%>\mathrm{B} 2=5.05 \%$. The least percentage of crude fiber was shown by B2 in all the beans samples analyzed. The result is contrary to the investigations by Mamta and Darshan [22] which stated that the cowpea bean vegetable had the highest crude fiber range from $17.19 \%$ to $5.54 \%$ in the samples analyzed.

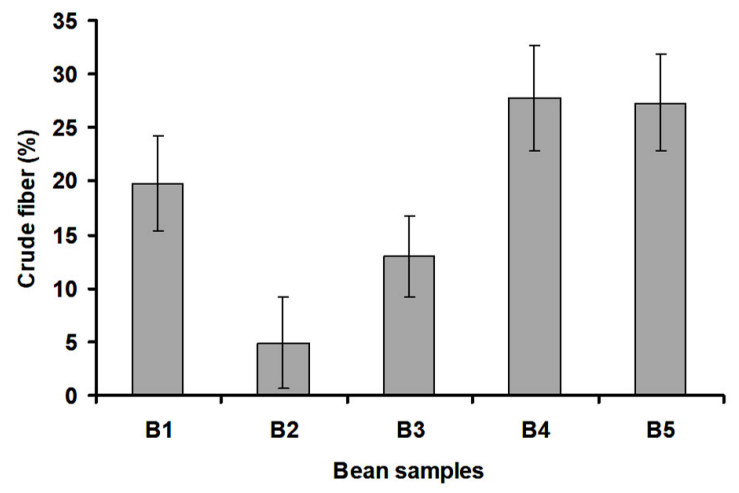

Fig. 1. Crude fiber of beans. Error bars represent standard deviation of triplicate.

\section{Organochlorinated Pesticides(OCP) Components of Beans Sample}

Illustrations in Table 1 shows the calibration curve quantitation database for pesticides residue components of the organochlorinated pesticides test of beans samples, whereby Table 1 showed the concentrations of fourteen major components pesticides residues in beans samples.
The pesticide residue component of poly phosphatedichlorodiphenyldichloroethane (p,p' DDD) showed the highest coefficient of 0.9993 with an expected retention time of 9.913 followed by pesticide residue of methoxychlor with a coefficient of 0.9992 and retention time of 11.498. However, pesticide residue of p,p'-DDT component, showed the lowest coefficient of 0.9913 with a retention time of 10.491 shown by the tested components samples of beans. The calibration curves for the pesticides in bean sample matrices (Figs. 2 to 15) differ slightly in terms of sensitivity and linear range from published results [7,23-25] and may indicate sample matrix interference that should be further studied in future works. Suggestions on sample matrix removal include the use of dispersive solid-phase extraction using a microporous metal-organic framework [26] and fabric phase sorptive extraction in conjunction with gas chromatography and mass spectrometry [27].

This study investigated the pesticides residue components of the organochlorinated pesticides in five different beans B1B5, which showed the presence of delta- lindane with a coefficient of $0.99808 \mathrm{ppm}$ and 5.353 retention time, Alphalindane with an amount of $0.990 \mathrm{ppm}$ and 5.851 retention time, beta- lindane with the amount of $0.997 \mathrm{ppm}$ and retention time of 6.039 , gamma- lindane with the amount of $0.995 \mathrm{ppm}$ and retention time of 6.566 , methoxychlor with $0.999 \mathrm{ppm}$ and retention time of 11.498, heptachlor with amount $0.996 \mathrm{ppm}$ retention time of 6.766 , aldrin showed $0.996 \mathrm{ppm}$ and retention time of 7.321, heptachlor epoxide showed $0.998 \mathrm{ppm}$ and retention time of 7.996, endosulfan 1 showed $0.998 \mathrm{ppm}$ and retention time of 8.631 , endosulfan 11 showed $0.994 \mathrm{ppm}$ and retention time of 9.81, p,p' DDE showed $0.999 \mathrm{ppm}$ and retention time of 9.078. p,p' DDD showed $0.999 \mathrm{ppm}$ and retention time of 9.913, p,p' DDT showed $0.991 \mathrm{ppm}$ and retention time of 10.49 and endrin showed $0.997 \mathrm{ppm}$ and retention time of 9.46 accordingly.

This indicated that all the 14 components of organochlorine phosphate of beans analyzed contain a lower amount of pesticides residue compared to $1.14 \mathrm{ppm}$ as reported by [19]. The amounts of components investigated are higher than the recommended values of $0.01 \mathrm{mg} / \mathrm{kg}$ to $0.2 \mathrm{mg} / \mathrm{kg}$ as stated by [28] therefore the beans consumed in Gombe metropolis are contaminated with chemicals of pesticides residues. The result also showed that $\mathrm{B} 4$ has the highest crude fiber content in decreasing order of $27.85 \%>\mathrm{B} 5=27.16 \%>\mathrm{B} 1=20 \%>\mathrm{B} 3$ $=12.55 \%>\mathrm{B} 2=5.05 \%$. The least percentage of crude fiber was shown by B2 in all the beans samples analyzed. The result is almost similar to the findings of [22] that crude fiber of cowpea beans ranges from $17.19 \%$ to $5.54 \%$

Table 1. OCP Calibration of Beans.

\begin{tabular}{lllll}
\hline Peak Name & $\begin{array}{l}\text { Exp } \\
\text { RetTime }\end{array}$ & Coef1 & $\begin{array}{l}\text { Corr } \\
\text { Coefficient type }\end{array}$ \\
\hline .delta.-Lindane & 5.353 & 10059 & 0.998 & linear (0,0) \\
alpha.-Lindane & 5.851 & 5989 & 0.999 & linear $(0,0)$ \\
.beta.-Lindane & 6.039 & 4144 & 0.998 & linear (0,0) \\
gamma.-Lindane & 6.566 & 4032 & 0.996 & linear (0,0) \\
Heptachlor & 6.766 & 9974 & 0.997 & linear (0,0) \\
Aldrin & 7.321 & 1697 & 0.997 & linear (0,0) \\
Heptachlor epoxide & 7.996 & 10591 & 0.998 & linear (0,0) \\
Endosulfan I & 8.631 & 2368 & 0.998 & linear (0,0) \\
p,p'-DDE & 9.078 & 18255 & 0.999 & linear (0,0) \\
Endrin & 9.461 & 2815 & 0.997 & linear (0,0) \\
Endosulfan II & 9.781 & 1228 & 0.994 & linear $(0,0)$ \\
p,p'-DDD & 9.913 & 27651 & 0.999 & linear (0,0) \\
p,p'-DDT & 10.491 & 22575 & 0.991 & linear (0,0) \\
Methoxychlor & 11.498 & 38318 & 0.999 & linear $(0,0)$
\end{tabular}




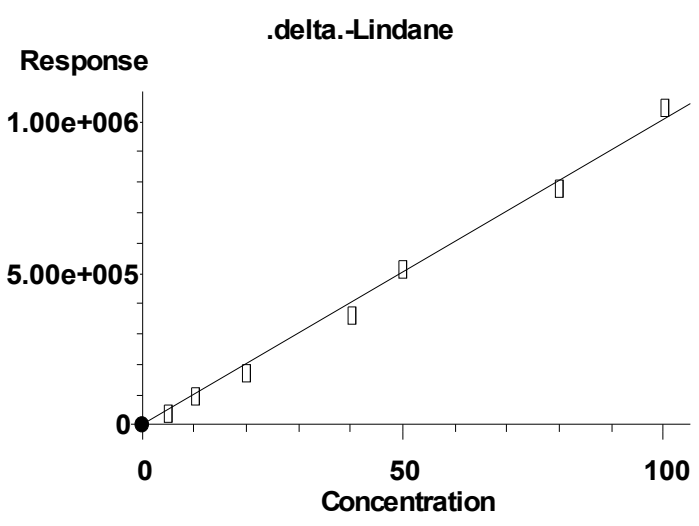

Fig. 2. OCP of delta-lindane calibration curve.

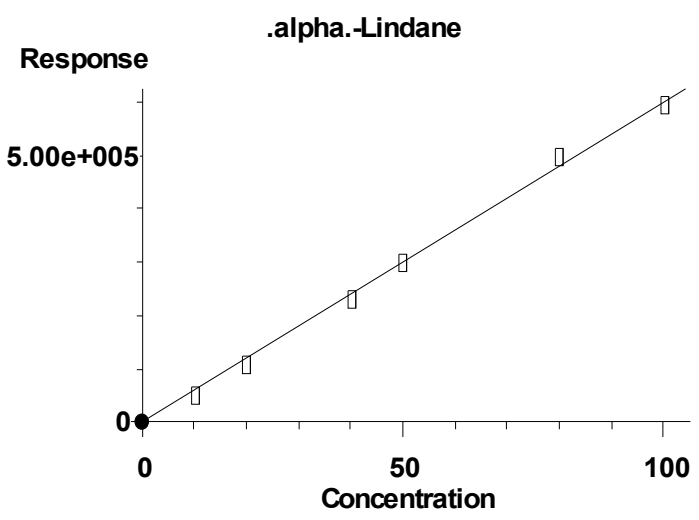

Fig. 3. OCP of alpha-lindane calibration curve.

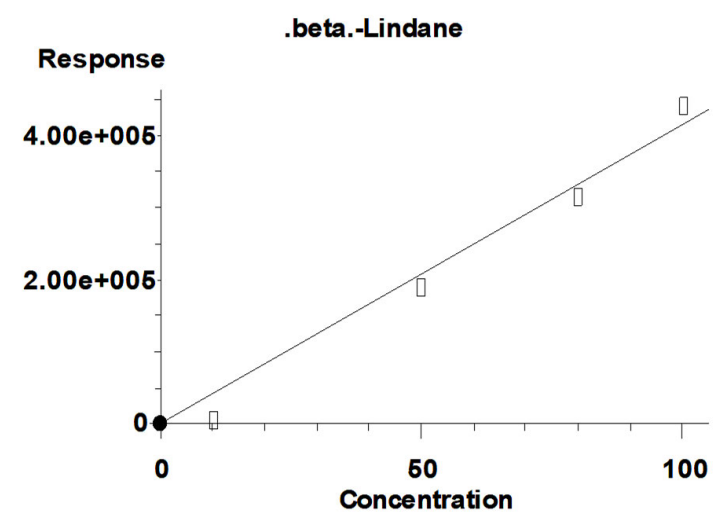

Fig. 4. OPC of beta-lindane calibration curve.

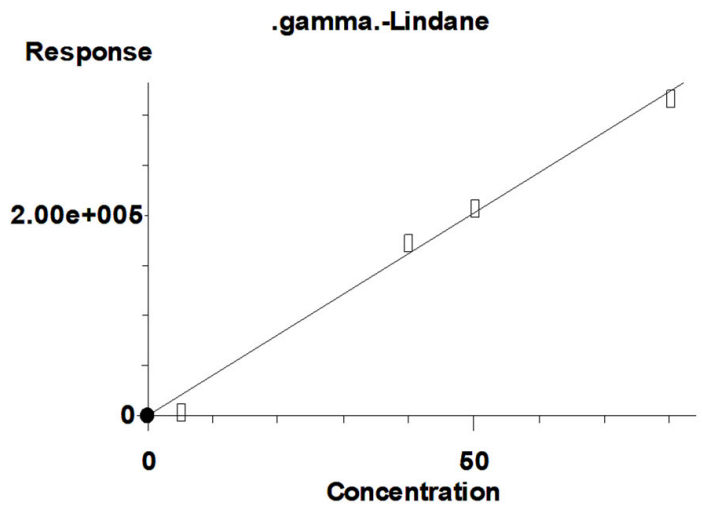

Fig. 5. OPC of gamma -lindane calibration curve.

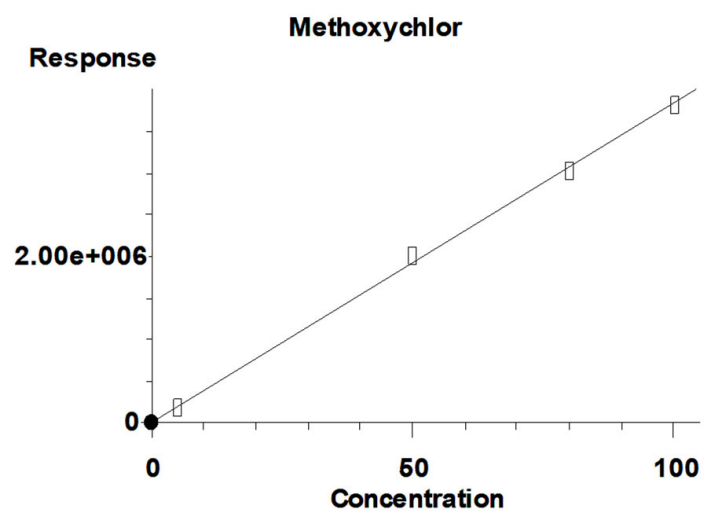

Fig. 6. OPC of Methoxychlor calibration curve

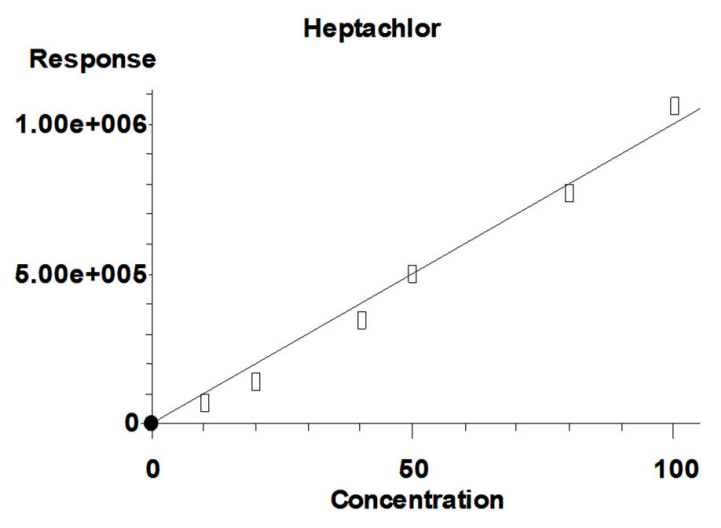

Fig. 7. OPC of Heptachlor calibration curve. 


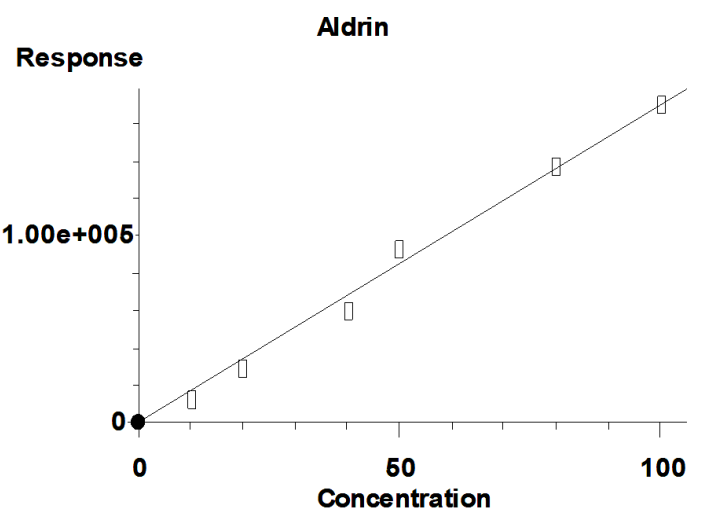

Fig. 8 OPC of Aldrin calibration curve.

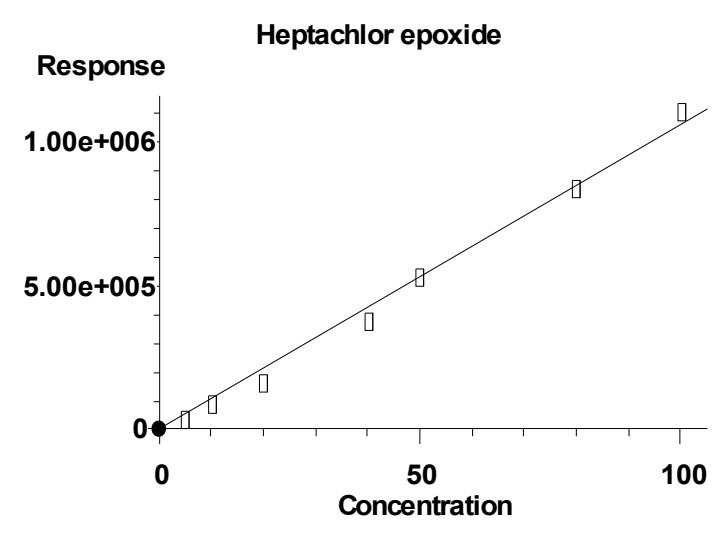

Fig. 9. OPC of Heptachlor epoxide calibration curve.

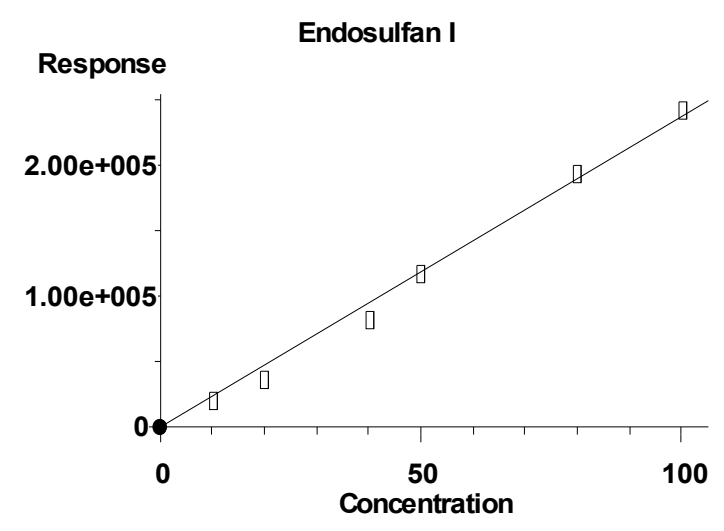

Fig. 10. OPC of Endosulfan 1 calibration curve.

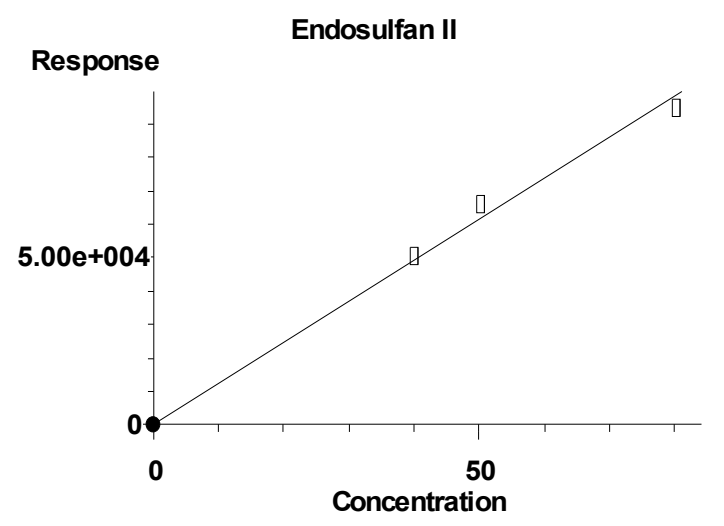

Fig. 11 OPC of Endosulfan 11 calibration curve.

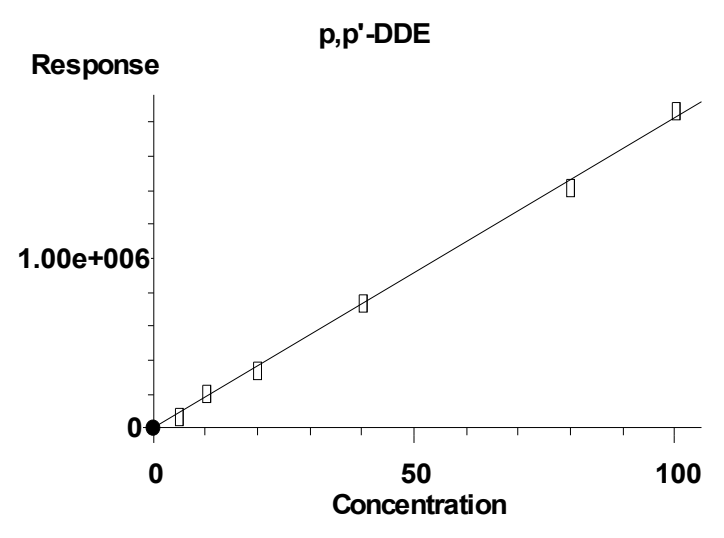

Fig. 12. OPC of p, p'- DDE calibration curve.

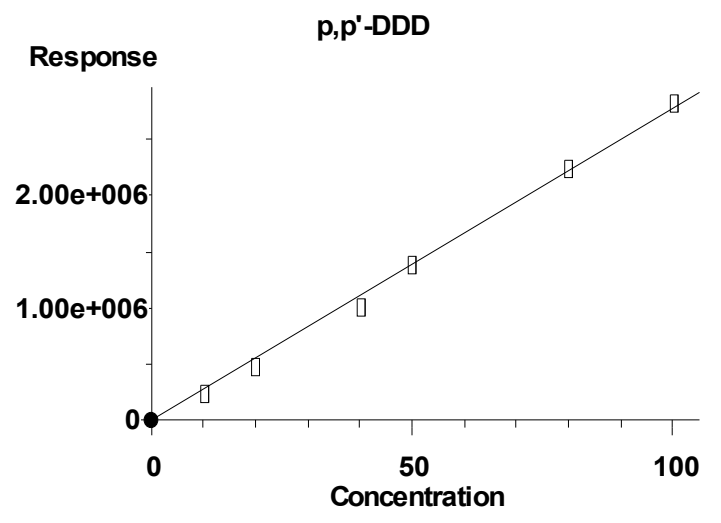

Fig. 13. OPC of p, p'- DDD calibration curve. 


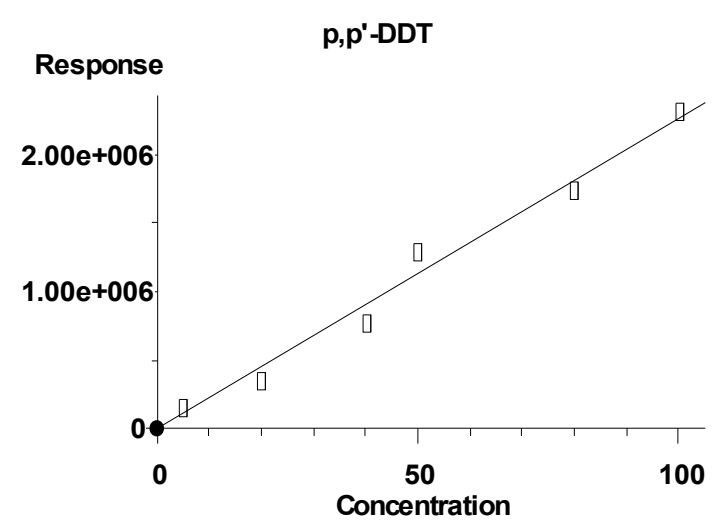

Fig. 14. OPC of p, p'- DDT calibration curve.

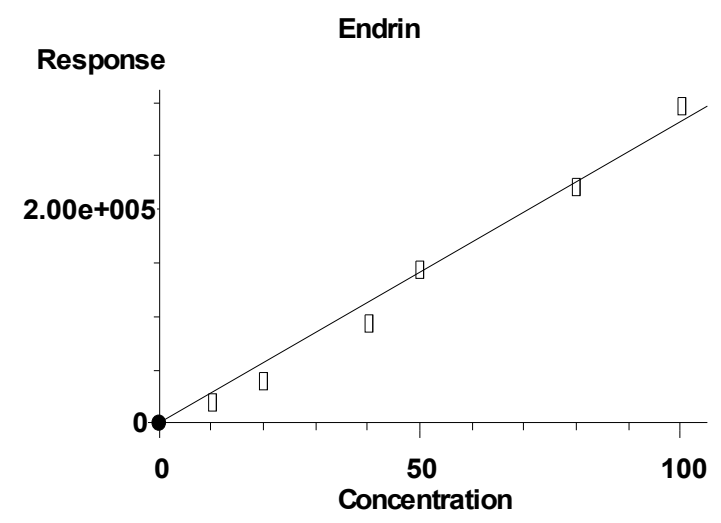

Fig. 15. OPC of Endrin calibration curve.

\section{CONCLUSION}

This study investigated the fibre content in beans and pesticides residue components of the organochlorinated pesticides in five different beans which showed the presence of delta- lindane, beta- lindane, gamma- lindane, methoxychlor, heptachlor, aldrin, heptachlor epoxide, endosulfan 1 and endosulfan 11 p,p' DDE, p,p' DDD and p,p' DDT. This indicated that all of the 14 types of organochlorine pesticides in beans shows a lower amount of pesticides residue than a previously published result. Despite this, the amount of organochlorine pesticides investigated are higher than the recommended values of 0.01 to $0.2 \mathrm{mg} / \mathrm{kg}$ suggesting that the beans consumed in the Gombe metropolis contained pesticide residues above the permissible limit.

\section{ACKNOWLEDGEMENTS}

The authors thank the Chief Technologies of Chemistry Department which novelty in person of Dr. Moh'd Falalu Yahaya of American University of Nigeria Yola, for the assistance rendered during instrumental analysis of (GC-MS) GasChromatography Mass Spectroscopy of Organochlorine Posphate (OCP) samples of beans.

\section{CONFLICTS OF INTEREST}

The authors have not declared any conflicts of interest in any case.

\section{RETERENCES}

1. Leong KH a, Benjamin Tan LL b, Mustafa AM c. Contamination levels of selected organochlorine and organophosphate pesticides in the Selangor River, Malaysia between 2002 and 2003. Chemosphere. 2007;66(6):1153-9.

2. Concha-Graña E, Turnes-Carou MI, Muniategui-Lorenzo S, LópezMahía P, Prada-Rodríguez D, Fernández-Fernández E. Evaluation of $\mathrm{HCH}$ isomers and metabolites in soils, leachates, river water and sediments of a highly contaminated area. Chemosphere. 2006;64(4):588-95.

3. Zhu Y, Liu H, Xi Z, Cheng H, Xu X. Organochlorine pesticides (DDTs and HCHs) in soils from the outskirts of Beijing, China. Chemosphere. 2005;60(6 SPEC. ISS.):770-8.

4. Quan L, Li S, Tian S, Xu H, Lin A, Gu L. Determination of Organochlorine Pesticides Residue in Ginseng Root by Orthogonal Array Design Soxhlet Extraction and Gas Chromatography. Chromatographia. 2004;59(1-2):89-93.

5. Nawab A, Aleem A, Malik A. Determination of organochlorine pesticides in agricultural soil with special reference to $\gamma-\mathrm{HCH}$ degradation by Pseudomonas strains. Bioresour Technol. 2003;88(1):41-6.

6. Meier PG, Fook DC, Lagler KF. Organochlorine pesticide residues in rice paddies in Malaysia, 1981. Bull Environ Contam Toxicol. 1983;30(1):351-7.

7. Rodríguez P, Permanyer J, Grases JM, González C. Confirmation method for the identification and determination of some organophosphorus and organochlorine pesticides in cocoa beans by gas chromatography-mass spectrometry. J Chromatogr B Biomed Sci App. 1991;562(1-2):547-53.

8. Popp J, Petö K, Nagy J. Pesticide productivity and food security. A review. Agron Sustain Dev. 2013 Jan 1;33(1):243-55.

9. Damalas CA, Eleftherohorinos IG. Pesticide Exposure, Safety Issues, and Risk Assessment Indicators. Int J Environ Res Public Health. 2011 May;8(5):1402-19.

10. Barnhoorn IEJ, van Dyk JC, Genthe B, Harding WR, Wagenaar GM, Bornman MS. Organochlorine pesticide levels in Clarias gariepinus from polluted freshwater impoundments in South Africa and associated human health risks. Chemosphere. 2015;120:391-7.

11. Mrema EJ, Rubino FM, Brambilla G, Moretto A, Tsatsakis AM, Colosio C. Persistent organochlorinated pesticides and mechanisms of their toxicity. Toxicology. 2013;307:74-88.

12. Buckley JD, Meadows AT, Kadin ME, Le Beau MM, Siegel S, Robison LL. Pesticide exposures in children with non-Hodgkin lymphoma. Cancer. 2000;89(11):2315-21.

13. Crinnion WJ. Chlorinated pesticides: threats to health and importance of detection. Altern Med Rev J Clin Ther. 2009 Dec;14(4):347-59.

14. Aksu Z. Application of biosorption for the removal of organic pollutants: A review. Process Biochem. 2005;40(3-4):997-1026.

15. Sweilum MA. Effect of sublethal toxicity of some pesticides on growth parameters, haematological properties and total production of Nile tilapia (Oreochromis niloticus L.) and water quality of ponds. Aquac Res. 2006;37(11):1079-89.

16. Maguire RJ. Review of the Persistence, Bioaccumulation and Toxicity of Tributyltin in Aquatic Environments in Relation to Canada's Toxic Substances Management Policy. Water Qual Res J. 2000 Nov 1;35(4):633-80.

17. Curl CL, Fenske RA, Elgethun K. Organophosphorus pesticide exposure of urban and suburban preschool children with organic and conventional diets. Environ Health Perspect. 2003 Mar;111(3):377-82.

18. Isegbe V, Habib M, Obaje J, Okoro S, Solomon S. Residues of Organochlorine Pesticide in Dried Beans (Vigna unguiculata). Int J Innov Food Nutr Sustain Agric. 2016;4(4):25-30.

19. Arjmandi R, Tavakol M, Shayeghi M. Determination of organophosphorus insecticide residues in the rice paddies. Int $\mathrm{J}$ Environ Sci Technol. 2010 Dec 1;7.

20. Usman YM, Nasiru Yahaya P, Modibbo U. U. Health risk assessment on humans by contamination of heavy metals in some edible crops and fish at Galena mining area of Nahuta, Alkaleri Local Government Area, Bauchi State, Nigeria. Afr J Pure Appl Chem. 2020 Jul 31;14(3):42-50. 
21. FSSAI [Internet]. [cited 2021 Dec 30]. Available from: https://fssai.gov.in/cms/manuals-of-methods-of-analysis-forvarious-food-products.php

22. Rani M, Punia D. Nutritional evaluation of products prepared from fresh beans. J Appl Nat Sci. 2017 Dec 1;9(4):2033-5.

23. Aoki Y, Takeda M, Uchiyama M. Comparative study of methods for the extraction of eleven organophosphorus pesticide residues in rice. J Assoc Off Anal Chem. 1975;58(6):1286-93.

24. Schenck FJ, Lehotay SJ. Does further clean-up reduce the matrix enhancement effect in gas chromatographic analysis of pesticide residues in food? J Chromatogr A. 2000;868(1):51-61.

25. De Miranda JAT, De Carvalho LMJ, De Castro IM, Dos Anjos MR, De Carvalho JLV, De MacÊdo Vieira AC. Heating, identification, and determination of pesticides residues in black bean samples. Chem Eng Trans. 2020;80:337-42.

26. Mao X, Xiao W, Wan Y, Li Z, Luo D, Yang H. Dispersive solidphase extraction using microporous metal-organic framework UiO66: Improving the matrix compounds removal for assaying pesticide residues in organic and conventional vegetables. Food Chem. 2021;345

27. Kaur R, Kaur R, Rani S, Malik AK, Kabir A, Furton KG. Application of fabric phase sorptive extraction with gas chromatography and mass spectrometry for the determination of organophosphorus pesticides in selected vegetable samples. J Sep Sci. 2019;42(4):862-70.

28. Iliya HA, Wannang NN, Falang KD, Nehemiah JA. Evaluation of Some Pesticide Residues in Stored Beans in Jos, Nigeria. West Afr J Pharmacol Drug Res. 2012;28:41-3. 